\title{
Unique pharmacological actions of atypical neuroleptic quetiapine: possible role in cell cycle/fate control
}

\author{
MA Kondo ${ }^{1}$, K Tajinda ${ }^{1,2}$, C Colantuoni ${ }^{3,5}$, H Hiyama $^{1,2}$, S Seshadri ${ }^{1}$, B Huang ${ }^{1}$, S Pou ${ }^{1}$, K Furukori $^{1}$, C Hookway ${ }^{1}$, H Jaaro-Peled ${ }^{1}$, \\ S-i Kano ${ }^{1}, \mathrm{~N}$ Matsuoka ${ }^{2}, \mathrm{~K} \mathrm{Harada}^{2}, \mathrm{~K} \mathrm{Ni}^{2}$, J Pevsner ${ }^{1,4}$ and A Sawa ${ }^{1}$
}

Quetiapine is an atypical neuroleptic with a pharmacological profile distinct from classic neuroleptics that function primarily via blockade of dopamine $D_{2}$ receptors. In the United States, quetiapine is currently approved for treating patients with schizophrenia, major depression and bipolar I disorder. Despite its widespread use, its cellular effects remain elusive. To address possible mechanisms, we chronically treated mice with quetiapine, haloperidol or vehicle and examined quetiapinespecific gene expression change in the frontal cortex. Through microarray analysis, we observed that several groups of genes were differentially expressed upon exposure to quetiapine compared with haloperidol or vehicle; among them, Cdkn1a, the gene encoding p21, exhibited the greatest fold change relative to haloperidol. The quetiapine-induced downregulation of p21/Cdkn1a was confirmed by real-time polymerase chain reaction and in situ hybridization. Consistent with single gene-level analyses, functional group analyses also indicated that gene sets associated with cell cycle/fate were differentially regulated in the quetiapine-treated group. In cortical cell cultures treated with quetiapine, p21/Cdkn1a was significantly downregulated in oligodendrocyte precursor cells and neurons, but not in astrocytes. We propose that cell cycle-associated intervention by quetiapine in the frontal cortex may underlie a unique efficacy of quetiapine compared with typical neuroleptics.

Translational Psychiatry (2013) 3, e243; doi:10.1038/tp.2013.19; published online 2 April 2013

\section{Introduction}

Understanding the molecular mechanisms that underlie the pathophysiology of major mental illnesses, such as schizophrenia and depression, is very important. It is possible to address some of the remaining fundamental questions by investigating novel actions of compounds currently in clinical use. A recent example is the report of a novel action of the neuroleptics clozapine and risperidone, via a heteromeric complex of $5-\mathrm{HT}_{2 \mathrm{~A}}$ and mGluR2 receptors. ${ }^{1,2}$

Neuroleptics have been in clinical use for schizophrenia since the $1950 \mathrm{~s}^{3}$ The hallmark of these first-generation drugs, including haloperidol and chlorpromazine, is antagonism of the dopamine $D_{2}$ receptor. ${ }^{4-6}$ Since the late 1980s, the so-called atypical neuroleptics, such as clozapine, have been introduced. Compared with the first-generation drugs, the atypical neuroleptics show somewhat better efficacy for the negative symptoms and cognitive dysfunction associated with schizophrenia. ${ }^{7,8}$ Furthermore, these drugs are also clinically effective in patients with mood disorders. For example, quetiapine has been approved by the US Food and Drug Administration for the treatment of bipolar depression and is frequently prescribed off-label for depression, anxiety, sleep disturbance and obsessive-compulsive disorder. $^{9-13}$ Therefore, in addition to $\mathrm{D}_{2}$ antagonism, this newer class of drug appears to have additional modes of action. Among the atypical neuroleptics that share a high affinity for serotonin $\left(5-\mathrm{HT}_{2 \mathrm{~A}}\right)$ but a relatively low affinity for dopamine $\left(D_{2}\right)$ receptors, quetiapine has a further unique profile with a high affinity for histamine $\left(\mathrm{H}_{1}\right)$ and $\alpha 1$-adrenergic receptors. ${ }^{14,15}$ It is not well understood how the interplay of quetiapine's various receptor-binding activities affects molecular pathways and translates to clinical efficacy. Hence, it seems necessary to look beyond the effects of the individual receptors within quetiapine's known receptor-binding profile to understand its overall therapeutic mechanism.

On the basis of its unique characteristics, we hypothesized that quetiapine would have novel pharmacological actions and operate via different pathways compared with the typical neuroleptics, potentially shedding light on new pathways involved in schizophrenia or mood disorders. To address this question, we compared the effects of chronic quetiapine treatment and haloperidol treatment on gene expression in

\footnotetext{
${ }^{1}$ Department of Psychiatry and Behavioral Sciences, Johns Hopkins School of Medicine, Baltimore, MD, USA; ${ }^{2}$ Pharmacology Research Labs, Astellas Pharma Inc., Tsukuba-shi, Ibaraki, Japan; ${ }^{3}$ Department of Biostatistics, Johns Hopkins Bloomberg School of Public Health, Baltimore, MD, USA and ${ }^{4}$ Hugo W Moser Research Institute at Kennedy Krieger, Baltimore, MD, USA

Correspondence: Professor A Sawa, Department of Psychiatry, Johns Hopkins University, 600 North Wolfe Street, Meyer 3-166, Baltimore, MD 21287, USA.

E-mail: asawa1@jhmi.edu

or Dr J Pevsner, Department of Psychiatry and Behavioral Sciences, Johns Hopkins University and Hugo W Moser Research Institute at Kennedy Krieger, Baltimore, MD 21287, USA.

E-mail: pevsner@kennedykrieger.org

${ }^{5}$ Current address: Lieber Institute for Brain Development, Baltimore, MD, USA.

Keywords: cell cycle; gene expression; mood disorders; neuroleptics; quetiapine; schizophrenia

Received 22 Decemeber 2012; accepted 1 January 2013
} 
mice. Haloperidol was selected as a representative typical neuroleptic that shows predominantly $D_{2}$ antagonism. ${ }^{16}$ Although some genes are affected by both drugs, a substantially larger number of genes are selectively changed by quetiapine at doses in which both compounds show similar efficacy against a representative preclinical marker for positive symptoms of schizophrenia. Here we highlight genes involved in cell cycle regulation that are modified by quetiapine, but not by haloperidol.

\section{Materials and methods}

Chronic administration of neuroleptics. Quetiapine fumarate was provided by AstraZeneca (Cheshire, UK) as a gift for an academic study. Haloperidol was purchased from Sigma (St Louis, MO, USA). Male CD-1 mice, 8 weeks of age, were purchased from Charles River (Wilmington, MA, USA). The chronic administration of neuroleptics was conducted at the Animal Core Facility at Johns Hopkins University. Mice were randomly divided into groups receiving vehicle $(0.5 \%$ methylcellulose solution, twice a day (b.i.d.)), quetiapine (at doses of 10 or $100 \mathrm{mg} \mathrm{kg}^{-1}$, b.i.d.) or haloperidol ( 0.3 or $1.0 \mathrm{mg} \mathrm{kg}^{-1}$, b.i.d.). The neuroleptics were prepared in $0.5 \%$ methylcellulose solution. Drug administration was carried out by oral gavage, two times daily at $0800 \mathrm{~h}$ and $2000 \mathrm{~h}$ for 28 days. Animals were killed $24 \mathrm{~h}$ after the last treatment. Frontal cortex and striatum were dissected for gene expression analysis, with one hemisphere used for microarray and the other for quantitative real-time polymerase chain reaction ( $q R T-P C R)$. A second cohort with vehicle or $100 \mathrm{mg} \mathrm{kg}^{-1}$ b.i.d. quetiapine only was used for in situ hybridization and to confirm qRT-PCR results. Experimental design is depicted in Supplementary Table 1. All animal procedures were performed in accordance with the Johns Hopkins Animal Care and Use Guidelines.

Methamphetamine-induced hyperlocomotion. As described previously, ${ }^{17}$ methamphetamine (METH)-induced hyperlocomotion was used to determine the appropriate drug doses for the experiments described above. Briefly, mice were administered quetiapine, haloperidol or vehicle $30 \mathrm{~min}, 8 \mathrm{~h}$ or $12 \mathrm{~h}$ before METH challenge. Immediately after injection with METH (1 $\mathrm{mg} \mathrm{kg}^{-1}$, subcutaneously) or saline, locomotor activity was measured for $30 \mathrm{~min}$ using SUPERMEX (Muromachi Kikai, Tokyo, Japan). Data were analyzed using CompAct AMS ver. 3.51 (Muromachi Kikai). Statistical analysis was conducted with one-way analysis of variance (ANOVA) followed by Dunnett's multiple comparison with METH + vehicle as control.

Microarray. Total RNA from the frontal cortex and striatum was extracted using the RNeasy Mini Kit (Qiagen, Valencia, CA, USA) according to the manufacturer's instructions. An on-column DNAse digestion step was included to remove genomic DNA contamination. For each dosage group, six samples with the best quality RNA were selected to generate two pooled microarray hybridization reactions (chips), each comprised of three total RNA samples. Total RNA of $800 \mathrm{ng}$ from each sample was combined to synthesize a microarray hybridization reaction with a one-cycle Amplification Kit
(Affymetrix, Santa Clara, CA, USA), using poly-dT as an initial primer, to enrich the $3^{\prime}$ end of transcripts. After the amplification, the double-stranded complementary DNA (cDNA) was transcribed and labeled with biotin-conjugated dUTP for microarray hybridization. The hybridization cocktail was fragmented by treatment at $65^{\circ} \mathrm{C}$ for $30 \mathrm{~min}$, and then hybridized onto the Affymetrix GeneChip MG430. Hybridization, washing and scanning were conducted according to the manufacturer's instructions. All microarray procedures were carried out at the Microarray Core Facility of Johns Hopkins University.

Microarray data analysis. Data analysis was performed using the Partek Genomics Suite software (version 6.5, Partek Inc., St Louis, MO, USA). Raw intensities were normalized using GC robust multiarray average. ${ }^{18}$ Principal components analysis was performed using a correlation matrix. ANOVA models with treatment, region (frontal cortex or striatum), dose and group as factors were generated to determine transcripts that were significantly regulated. Of the 45101 transcripts, those with no RefSeq identifier and/or no gene symbol were removed, leaving 35892 transcripts. Gene set enrichment analysis was performed on the frontal cortex data using the Partek software according to the method of Subramanian and co-workers. ${ }^{19}$ The microarray data from both doses were combined for each drug to increase statistical power for the gene set enrichment analysis. The raw microarray data have been deposited in the Gene Expression Omnibus archive at the National Center for Biotechnology Information (Bethesda, MD, USA) (accession GSE45229).

Quantitative Real-Time PCR. qRT-PCR was performed at the Genetic Resources Core Facility of Johns Hopkins University. cDNA was synthesized from $1 \mu \mathrm{g}$ of total RNA using SuperScript III First-Strand Synthesis System with oligodT priming (Invitrogen, Grand Island, NY, USA). The qRT-PCR reaction contained 500 -fold diluted CDNA from the synthesis reaction, $1 \times$ SYBR GreenER reagent (Invitrogen) and 200 nм specific forward and reverse primers in a $10 \mu \mathrm{l}$ reaction volume. Gapdh expression levels were used to normalize the expression data. Primer sequences were as follows: (mouse primers) Cdkn1a (NM_007669)_forward, 5'-TGTACAA GGAGCCAGGCCA-3'; reverse, 5'-TGTGAGCTCCCTTAGC CCC-3'; Gapdh (NM_008084)_forward, 5'-TGCAGTGG CAAAGTGGAGATT-3'; reverse, 5'-TTGAATTTGCCGTG AGTGGA-3'. (Rat primers) Cdkn1a (NM_080782)—forward, 5'-CGCTCGGATTGTAAACCTCC-3'; reverse, 5'-GGGAC AGTGCAGGGTGTGAT-3'; Gapdh (NM_017008)—forward, 5'-AGCCCTCCCTTCTCTCGAATA-3'; reverse, 5'-TTTTGAG GGTGCAGCGAACT-3'.

Primers were designed using PrimerExpress 2.0 (Applied Biosystems, Carlsbad, CA, USA). The real-time PCR reaction and measurement was carried out with Applied Biosystems PRISM7900. The PCR reaction condition was as follows: $50{ }^{\circ} \mathrm{C}$ for $2 \mathrm{~min}, 95^{\circ} \mathrm{C}$ for $10 \mathrm{~min}$, followed by 40 cycles of $95^{\circ} \mathrm{C}$ for $15 \mathrm{~s}$ and $60^{\circ} \mathrm{C}$ for $1 \mathrm{~min}$. A dissociation curve step was added at the end to verify the presence of a single amplicon in the reaction.

In situ hybridization and immunohistochemistry. Mouse brains were perfused with $4 \%$ paraformaldehyde, embedded 
in Tissue-Tek Optimum Cutting Temperature Compound (Sakura Finetek, Torrance, CA, USA) and stored at $-80^{\circ} \mathrm{C}$. Coronal sections ( $20 \mu \mathrm{m}$ thick) were cut using a cryostat, and then mounted on poly-L-lysine-coated slides that were paired so that adjacent sections could be used for immunohistochemistry and in situ hybridization. Sections used for immunohistochemistry were permeablized and blocked in a solution of $0.2 \%$ Triton $\mathrm{X}-100$ in phosphate-buffered saline, $10 \%$ donkey serum and $1 \%$ bovine serum albumin for $1 \mathrm{~h}$; incubated overnight at $4{ }^{\circ} \mathrm{C}$ with 1:750 dilution of anti-NeuN, clone A60 (Millipore, Billerica, MA, USA); incubated $1 \mathrm{~h}$ with 1:400 dilution secondary donkey anti-mouse Alexa 568; and incubated with 1:10000 dilution 4',6-diamidino-2-phenylindole for $5 \mathrm{~min}$. The protocol for situ hybridization was as published with minor modifications. ${ }^{20}$ Digoxigenin-labeled cRNA probes were used on the perfused mouse coronal sections described above. Probes (300 ng) were used at $37^{\circ} \mathrm{C}$ and anti-digoxigenin alkaline phosphatase Fab fragments (Roche, Indianapolis, IN, USA) were applied to sections at a dilution of 1:1000.

Sense probe sequence for Cdkn1a was as follows: 5'-ACTTCGTCTGGGAGCGCGTTCGGAGCCTAGGGCTG CCCAAGGTCTACCTGAGCCCTGGGTCCCGCAGCCGTG ACGACCTGGGAGGGGACAAGAGGCCCAGTACTTCCTC TGCCCTGCTGCAGGGGCCAGCTCCGGAGGACCACGT GGCCTTGTCGCTGTCTTGCACTCTGGTGTCTGAGCGG CCTGAAGATTCCCCGGGTGGGCCCGGAACATCTCAGG GCCGAAAACGGAGGCAGACCAGCCTGACAGATTTCTA TCACTCCAAGCGCAGATTGGTCTTCTGCAAGAGAAAAC CCTG-3'. The antisense probe was the reverse complement of the above. The probe was designed to cross an intron/exon boundary. Cdkn1a mRNA was quantified by normalizing the signal in the vehicle and quetiapine-treated antisense samples ( $n=3$ each) to the sense slide.

Cell culture. Rat cortical neuron, astrocyte and oligodendrocyte precursor cells (OPCs) were prepared as described previously. ${ }^{21-23}$ Briefly, Sprague-Dawley rat brains at embryonic day 18.5 (E18.5) were used for primary neurons. Cells were seeded onto poly-D-lysine-coated plates in a Neurobasal medium supplemented with glutamate and B27. For cortical primary astrocyte and OPC, the frontal cortex was isolated at postnatal day 3. OPCs overlaying astrocytes were separated by mechanical agitation after 10-14 days of culture and transferred to poly-D-lysine plates. Neurons, primary astrocytes and OPCs were challenged for $48 \mathrm{~h}$ with $10 \mu \mathrm{m}$ quetiapine dissolved in $0.1 \%$ dimethyl sulfoxide or $0.1 \%$ dimethyl sulfoxide only (vehicle), and then harvested for RNA extraction and subsequent qRT-PCR.

Statistical analysis for qRT-PCR and in situ hybridization. Where multiple groups were involved, statistical analysis was conducted using one-way ANOVA and post hoc Dunnett's multiple comparison with the control group. An unpaired $t$-test was used to compare two groups. Results were considered significant at $\alpha=0.05$.

\section{Results}

In humans, therapeutic quetiapine doses range from 150 to $750 \mathrm{mg} \mathrm{kg}^{-1}$ per day. ${ }^{14,24}$ The corresponding dose for use in
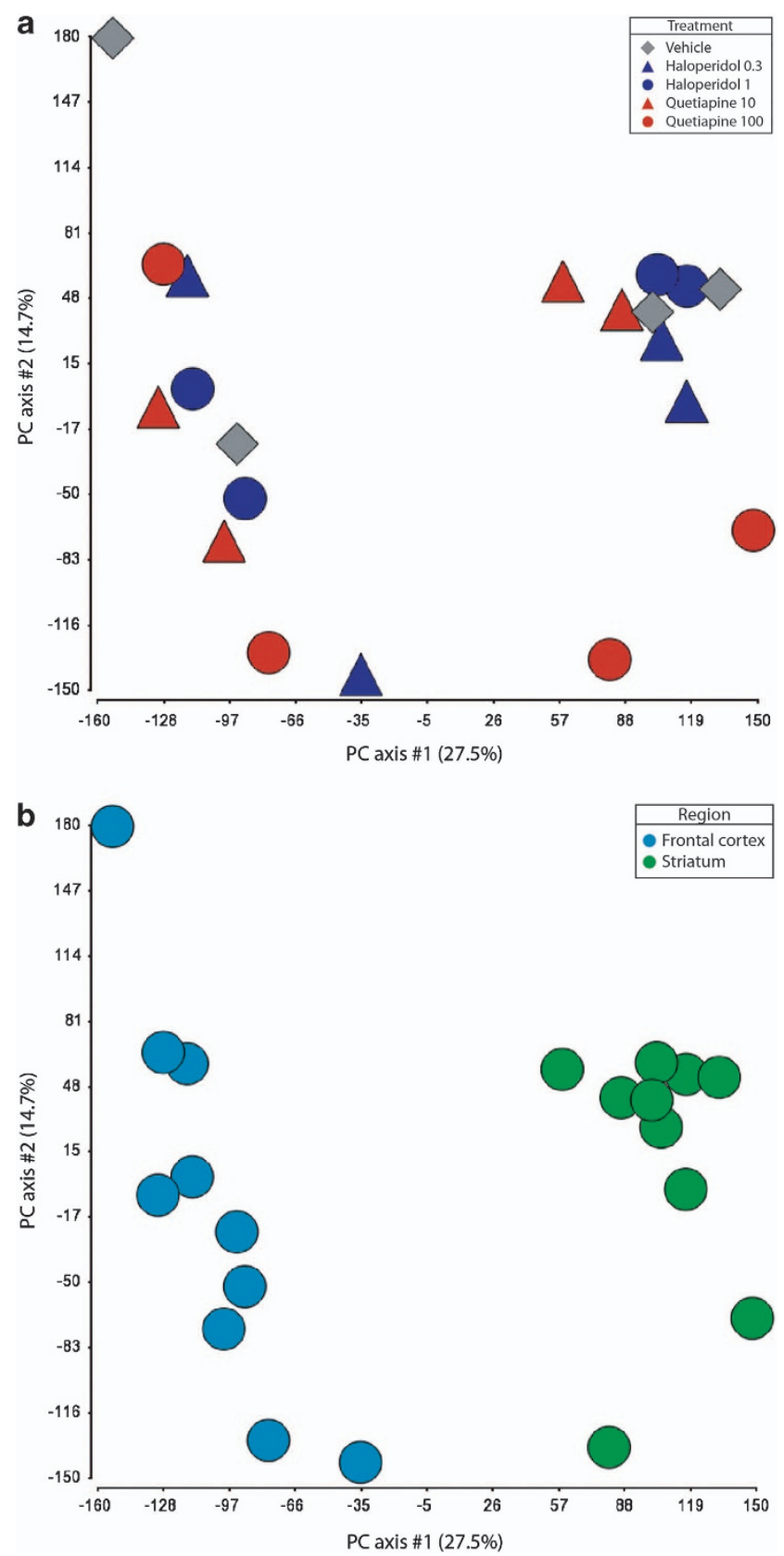

Figure 1 Principal components $(\mathrm{PC})$ analysis plot of gene expression data. The $\mathrm{PC}$ analysis displays the relationship between the 20 samples ( 5 treatments $\times 2$ brain regions $\times 2$ chips each) in the microarray, each representing 45101 transcripts; by treatment-drug and dose (a); and by region (b).

rodents is not clear, partly due to different drug metabolism among species. Therefore, we selected experimental doses of quetiapine and haloperidol based on their preventive effects on METH-induced hyperlocomotor activity in mice, a representative preclinical marker for positive symptoms of schizophrenia. Haloperidol significantly decreased locomotor activity in a dosedependent manner at the 0.5 and $8 \mathrm{~h}$ time points following METH administration; however, its effect was diminished by the $12 \mathrm{~h}$ time point (Supplementary Figure 1A). Quetiapine elicited a statistically significant, dose-dependent decrease in 
Table 1 Single gene analysis by ANOVA: high-dose haloperidol versus high-dose quetiapine in the frontal cortex

\begin{tabular}{|c|c|c|c|c|}
\hline Index & Gene symbol & Gene title & $\mathrm{P}$-value & QUE fold change \\
\hline 1 & Clcn5 & Chloride channel 5 & $5.06 \mathrm{E}-09$ & Down (1.48) \\
\hline 2 & Piwil2 & Piwi-like homolog 2 (Drosophila) & $3.31 \mathrm{E}-07$ & Up $(1.31)$ \\
\hline 3 & Tnfrsf25 & Tumor necrosis factor receptor superfamily, member 25 & $6.44 \mathrm{E}-07$ & Down (3.19) \\
\hline 4 & P4ha1 & Procollagen-proline, 2-oxoglutarate 4-dioxygenase (proline 4-hydroxylase), alpha & $7.80 \mathrm{E}-07$ & Down (1.85) \\
\hline 5 & Sidt1 & SID1 transmembrane family, member 1 & $7.91 \mathrm{E}-07$ & Down (2.01) \\
\hline 6 & 9030224M15Rik & RIKEN cDNA 9030224M15 gene & $9.48 \mathrm{E}-07$ & Up (1.34) \\
\hline 7 & Polr3k & Polymerase (RNA) III (DNA-directed) polypeptide K & $1.50 E-06$ & Down (1.68) \\
\hline 8 & Osr1 & Odd-skipped related 1 (Drosophila) & $4.05 E-06$ & Down (2.12) \\
\hline 9 & Top1 & Topoisomerase (DNA) I & $6.19 E-06$ & Down (1.24) \\
\hline 10 & Ptk2 & PTK2 protein tyrosine kinase 2 & $6.53 E-06$ & Down (2.68) \\
\hline 11 & Dnajc3 & DnaJ (Hsp40) homolog, subfamily C, member 3 & $7.60 E-06$ & Down (1.83) \\
\hline 12 & Hdgf & Hepatoma-derived growth factor & $7.93 E-06$ & Up $(2.25)$ \\
\hline 13 & Lifr & Leukemia inhibitory factor receptor & $8.13 E-06$ & Up (1.35) \\
\hline 14 & Ccl12 & Chemokine (C-C motif) ligand 12 & $9.08 \mathrm{E}-06$ & Up (1.37) \\
\hline 15 & Slco1a4 & Solute carrier organic anion transporter family, member 1 a4 & $9.12 E-06$ & Up (1.96) \\
\hline 16 & Ttc39b & Tetratricopeptide repeat domain $39 B$ & $1.02 E-05$ & Down (1.18) \\
\hline 17 & A330021E22Rik & RIKEN cDNA A330021E22 gene & $1.30 \mathrm{E}-05$ & Up (1.29) \\
\hline 18 & Colkn1a & Cyclin-dependent kinase inhibitor $1 A(P 21)$ & $1.68 \mathrm{E}-05$ & Down (6.19) \\
\hline 19 & Ddit3 & DNA damage-inducible transcript 3 & $1.73 E-05$ & Down (1.51) \\
\hline 20 & Nxf7 & Nuclear RNA export factor 7 & $2.11 \mathrm{E}-05$ & Down (1.14) \\
\hline 21 & Usp2 & Ubiquitin-specific peptidase 2 & $2.46 \mathrm{E}-05$ & Up (1.69) \\
\hline 22 & Ccar1 & Cell division cycle and apoptosis regulator 1 & $2.64 \mathrm{E}-05$ & Down (1.37) \\
\hline 23 & Spata19 & Spermatogenesis-associated 19 & $2.72 E-05$ & Up $(1.21)$ \\
\hline
\end{tabular}

Abbreviations: ANOVA, analysis of variance; b.i.d., twice a day; QUE, quetiapine treated.

In the frontal cortex, high-dose haloperidol ( $1 \mathrm{mg} \mathrm{kg}^{-1}$, b.i.d.) and high-dose quetiapine (100 $\mathrm{mg} \mathrm{kg}^{-1}$, b.i.d.) treatments were analyzed by ANOVA to identify transcripts with a false discovery rate of $<0.05$. In all, 23 transcripts satisfied this criterion. There was a significant, sixfold decrease in the expression of $C d k n 1 a$ (p21) in the frontal cortex of quetiapine-treated mice compared with haloperidol-treated mice.

Table 2 Gene set enrichment analysis of functional groups differentially regulated in the frontal cortex between haloperidol- and quetiapine-treated mice

\begin{tabular}{|c|c|c|c|c|}
\hline Index & Gene set description & $\begin{array}{l}\text { No. of } \\
\text { genes }\end{array}$ & $F D R$ & $\begin{array}{c}\text { Downregulated } \\
\text { in QUE }\end{array}$ \\
\hline 1 & Negative regulation of vasoconstriction & 16 & 0.028 & Yes \\
\hline 2 & Estrogen metabolic process & 20 & 0.030 & Yes \\
\hline 3 & Vesicle docking involved in exocytosis & 40 & 0.032 & No \\
\hline 4 & Metabotropic glutamate receptor signaling pathway & 15 & 0.034 & Yes \\
\hline 5 & Central nervous system neuron differentiation & 32 & 0.034 & Yes \\
\hline 6 & Stem cell factor receptor binding & 17 & 0.035 & Yes \\
\hline 7 & Negative regulation of cell cycle arrest & 17 & 0.037 & Yes \\
\hline 8 & Response to electrical stimulus & 16 & 0.037 & Yes \\
\hline 9 & Regulation of signal transduction & 44 & 0.038 & Yes \\
\hline 10 & ER overload response & 31 & 0.039 & Yes \\
\hline 11 & Regulation of respiratory gaseous exchange & 15 & 0.041 & Yes \\
\hline 12 & Androgen metabolic process & 24 & 0.043 & Yes \\
\hline 13 & Response to stress & 240 & 0.050 & Yes \\
\hline 14 & Cellular response to glucose starvation & 19 & 0.059 & Yes \\
\hline 15 & Circadian rhythm & 59 & 0.062 & Yes \\
\hline 16 & COPI-coated vesicle & 15 & 0.064 & No \\
\hline 17 & Inactivation of MAPK activity & 42 & 0.066 & Yes \\
\hline 18 & Skeletal muscle fiber development & 24 & 0.072 & Yes \\
\hline 19 & Contractile fiber & 34 & 0.079 & Yes \\
\hline 20 & mRNA catabolic process & 33 & 0.088 & Yes \\
\hline 21 & Positive regulation of cyclin-dependent protein kinase activity & 25 & 0.089 & Yes \\
\hline 22 & Protein kinase inhibitor activity & 38 & 0.089 & Yes \\
\hline 23 & Chaperone-mediated protein folding requiring cofactor & 34 & 0.098 & Yes \\
\hline
\end{tabular}

Abbreviations: FDR, false discovery rate; QUE, quetiapine treated.

In all, 23 gene sets satisfied an FDR of 0.1 .

METH-induced hyperlocomotion $0.5 \mathrm{~h}$ after administration at doses of 10,30 and $100 \mathrm{mg} \mathrm{kg}^{-1}$ (Supplementary Figure 1B). There were quetiapine-induced, dose-dependent decreases in locomotor activity at 8 and $12 \mathrm{~h}$, with a statistically significant decrease for the highest dose at $8 \mathrm{~h}$. On the basis of the response to this representative preclinical marker, we selected
$1 \mathrm{mg} \mathrm{kg}^{-1}$ haloperidol and $100 \mathrm{mg} \mathrm{kg}^{-1}$ quetiapine as the mini mum doses most likely to be continuously effective under conditions of two times daily injections (every $12 \mathrm{~h}$ ) over a 28-day period. Groups with chronic administration at a lower dose of haloperidol $\left(0.3 \mathrm{mg} \mathrm{kg}^{-1}\right.$, b.i.d.) and quetiapine $\left(10 \mathrm{mg} \mathrm{kg}^{-1}\right.$, b.i.d.) were also included in the study for reference purposes. 


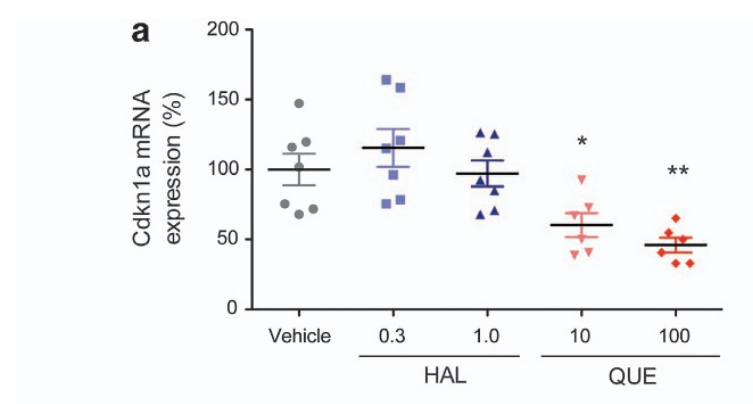

b
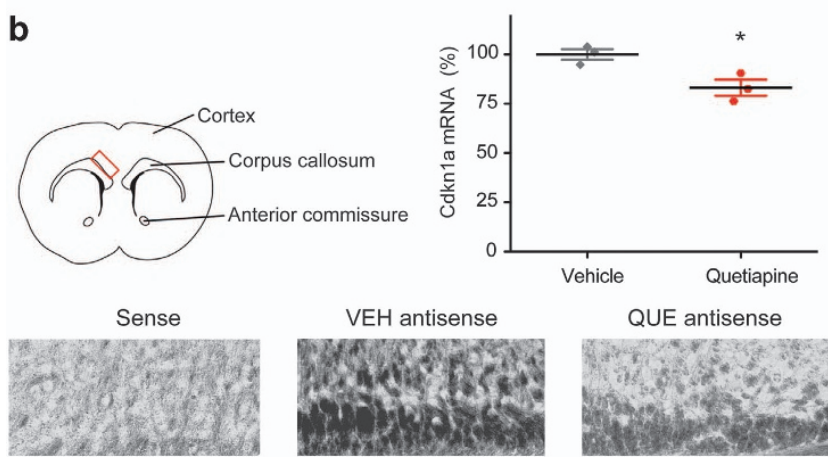

QUE antisense

Figure 2 Frontal cortex, analysis of $C d k n 1 a$ expression by quantitative real-time polymerase chain reaction (qRT-PCR) and in situ hybridization. (a) qRT-PCR confirmed downregulation of the cell cycle regulator gene Cdkn1a in quetiapinetreated but not haloperidol-treated mice. Gapdh expression was used as an internal control. The results are shown as mean \pm s.e.m., with vehicle as $100 \%$. Statistical analysis was conducted with analysis of variance (ANOVA) and post hoc Dunnett's multiple comparison. ${ }^{*} P<0.05,{ }^{* *} P<0.01$ versus vehicle-treated mice. $\mathrm{HAL}=$ haloperidol; QUE = quetiapine. (b) In situ hybridization of Cdkn1a in the vehicle and $100 \mathrm{mg} \mathrm{kg}^{-1}$ (b.i.d.) quetiapine-treated brain slices ( $n=3$ each). Red box in cartoon shows region quantified. Background is indicated by the sense slide (left), antisense slide for mice chronically exposed to vehicle (middle), antisense slide for mice chronically treated with $100 \mathrm{mg} \mathrm{kg}^{-1}$ (b.i.d.) quetiapine (right). Dark staining indicates hybridization of $C d k n 1 a$ probe (representative images). Absorbance in the antisense slides were normalized to sense for quantification. The results are shown as mean \pm s.e.m., with vehicle as $100 \%$. Statistical analysis was conducted with unpaired $t$-test. ${ }^{*} P<0.05$

RNA transcript levels from the brains of animals chronically administered with drug or vehicle were measured and analyzed using principal components analysis. This technique is useful to visualize the relationships among the samples from different brain regions, treatments and doses. There were no clear differences between samples across all RNA transcript values based on drug or dose (Figure 1a). As the drugs and doses selected were expected to have discrete but not pervasive effects on transcription, these results indicate appropriate data normalization. The robustness of data normalization is also evident in the volcano plot (Supplementary Figure 2). In contrast, there was a robust separation of samples across principal component axis 1 based on gene expression values from region (frontal cortex versus striatum), suggesting the importance of region-specific molecular profiling for further understanding drug effects on the brain (Figure 1b).

As region-specific analysis appeared crucial in this study, we addressed RNA transcript changes specifically in the frontal cortex. The rationale for focusing on this brain region was to explore a novel mechanism of quetiapine; while the
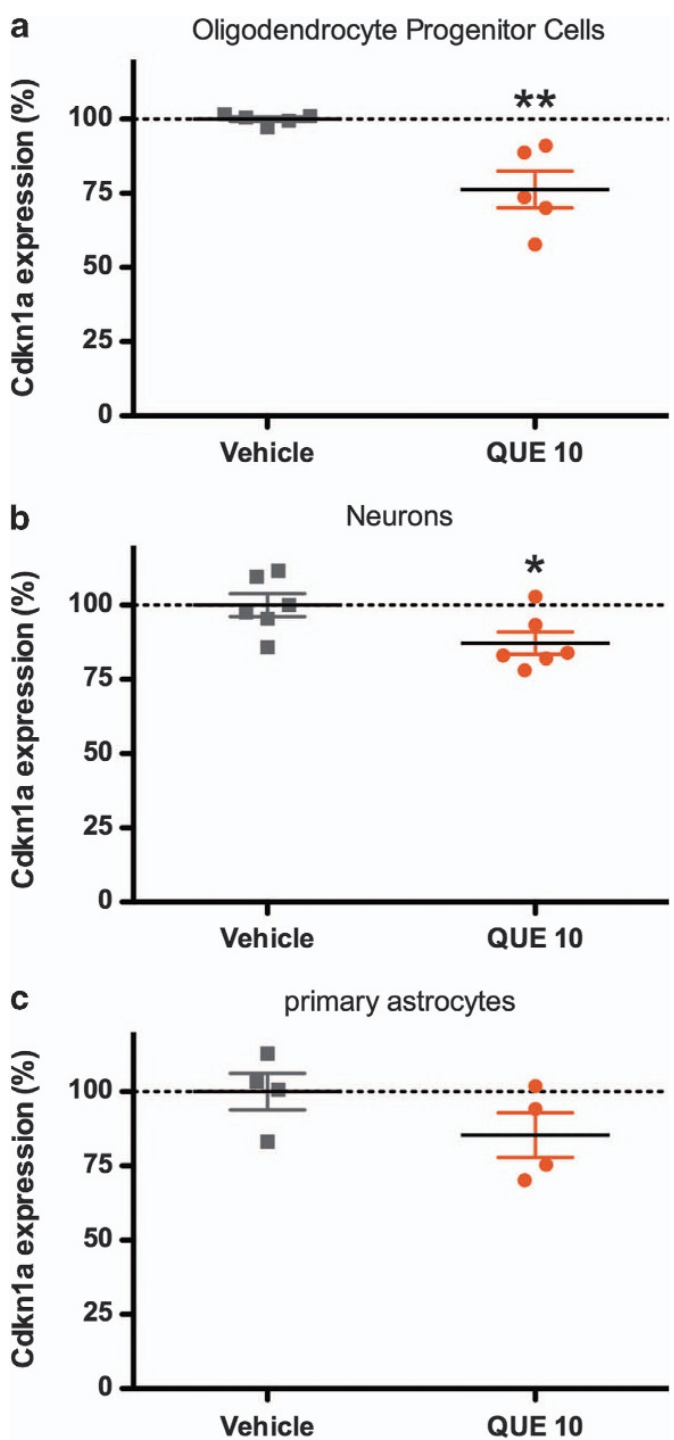

Figure 3 Quantitative real-time polymerase chain reaction (qRT-PCR) analysis of rat cortical primary astrocytes, neurons and oligodendrocyte progenitor cells. The effect of $10 \mu \mathrm{m}$ quetiapine on the expression of Cdkn1a by oligodendrocyte progenitor cells (a), neurons (b) and primary astrocytes (c) was assessed. One representative result of three independent experiments is shown. Expression of Cdkn1a was normalized to Gapdh expression. The results are shown as mean \pm s.e.m., with vehicle as $100 \%$. Statistical analysis was conducted with unpaired $t$-test. ${ }^{*} P<0.05,{ }^{* *} P<0.01$.

classic action of neuroleptics is believed to be mediated mainly by striatal dopamine $D_{2}$ receptors, quetiapine's unique clinical efficacy, especially for mood and cognition, may come from its influence on the frontal cortex. At a false discovery rate of 0.05 , analysis of haloperidol $\left(1 \mathrm{mg} \mathrm{kg}^{-1}\right.$, b.i.d.) versus vehicle revealed 12 differentially regulated transcripts (Supplementary Table 2), while quetiapine (100 $\mathrm{mg} \mathrm{kg}^{-1}$, b.i.d.) versus vehicle resulted in 37 differentially regulated transcripts (Supplementary Table 3). A comparison of highdose quetiapine $\left(100 \mathrm{mg} \mathrm{kg}^{-1}\right.$, b.i.d.) against high-dose haloperidol ( $1 \mathrm{mg} \mathrm{kg}^{-1}$, b.i.d.) revealed 23 differentially regulated transcripts in the frontal cortex (Table 1). Within this group, the significantly regulated transcript with the 
largest fold change was Cdkn1a, which was downregulated 6.19-fold by quetiapine treatment. Cdkn1a encodes p21, a cyclin-dependent kinase inhibitor that is a key downstream mediator of p53 and has a critical role in cell cycle/fate control. Other significantly regulated transcripts implicated in cell cycle control included Ccar1 (cell division cycle and apoptosis regulator 1), Ddit3 (DNA damage-inducible transcript 3), Lifr (leukemia inhibitory factor receptor), Osr1 (odd-skipped related 1) and Usp2 (ubiquitin-specific peptidase 2). Gene set enrichment analysis also underscored transcripts associated with cell cycle fate control as specifically influenced by quetiapine (Table 2 reports the functional groups with a corrected $P$-value $<0.1)$. The differentially regulated functional groups included 'central nervous system neuron differentiation', 'negative regulation of cell cycle arrest', 'positive regulation of cyclin-dependent protein kinase activity' and 'circadian rhythm', These gene sets were downregulated by quetiapine treatment relative to haloperidol.

Until recently, appreciation of the potential pathobiological significance of molecules involved in cell cycle control, including p21/Cdkn1a, was mostly limited to the field of cancer research. ${ }^{25}$ However, recent reports suggest that dysregulation of cell cycle molecules in postmitotic neurons may also have pathological significance in brain disorders. ${ }^{26-28}$ Focusing our attention on p21/Cdkn1a, qRT-PCR and in situ hybridization were used to further validate the expression change in mouse brains chronically treated with quetiapine. qRT-PCR on the frontal cortex tissue confirmed that quetiapine, but not haloperidol, induced a significant dose-dependent reduction of p21/Cdkn1a transcript (Figure 2a). In situ hybridization of the frontal cortex sections from quetiapinetreated mice demonstrated a prominent reduction of $\mathrm{p} 21 /$ Cdkn1a transcript compared with vehicle-treated mice (Figure 2b). Immunohistochemistry on adjacent brain sections indicated that part of the $\mathrm{p} 21 / \mathrm{Cdkn1a}$ reduction corresponds with NeuN-positive cells (Supplementary Figure 3).

Primary cell culture of neurons, astrocytes and OPCs were used to test whether quetiapine's influence on p21/Cdkn1a expression is cell type-specific (Figure 3). Treatment with $10 \mu \mathrm{m}$ quetiapine for $48 \mathrm{~h}$ resulted in a robust decrease in $\mathrm{p} 21 /$ Cdkn1a expression in OPCs and primary neurons. In contrast, significant change to p21/Cdkn1a expression was not observed in astrocytes.

\section{Discussion}

The aim of this study was to identify novel pathways potentially involved in schizophrenia and/or mood disorders by investigating quetiapine-, but not haloperidol-, induced molecular expression changes in the frontal cortex. Functional group analysis and individual gene assessments resulted in the identification of significantly altered molecules involved in cell cycle regulation, especially Cdkn1a, the gene encoding p21. Our in situ hybridization results indicate that the change seems to occur at least in deep layer neurons in the adult brain, and systematic analysis of cell culture indicate that quetiapine significantly downregulates the expression of Cdkn1a in OPCs and primary neurons, but not in astrocytes.

Quetiapine is postulated to have molecular and cellular actions that are unique compared with other neuroleptics.
This is particularly important in considering the efficacy of quetiapine for clinical manifestations beyond psychosis. ${ }^{29-33}$ Our study suggests that part of quetiapine's therapeutic profile may involve normalization of molecules regulating cell cycle/ fate control. Interestingly, aberrant regulation of cell cycle and alteration to cell cycle-associated molecules has been reported in schizophrenia and mood disorder studies using human post-mortem brains and biopsied cells. ${ }^{28,34-39}$ Human genetic studies have also identified rare genetic variants, including those in the KCTD13 and DISC1 genes associated with schizophrenia, mood disorders and autism, which have biological roles in the regulation of progenitor cell proliferation. ${ }^{40,41}$ Also in line with the concept of cell cycle dysfunction in major mental illnesses, the mood stabilizer lithium and antidepressants reportedly affect the Wnt signaling pathway, which fundamentally modulates cell cycle and fate. ${ }^{42,43}$ Furthermore, $\mathrm{Li}$ and co-workers ${ }^{44}$ reported that quetiapine influences the proliferation of neural progenitor cells and oligodendrocyte differentiation, thereby attenuating white matter pathology and associated phenotypes in rodents. ${ }^{45,46}$ Our observation of downregulated p21/Cdkn1a, a key molecule in cell cycle regulation, may underlie this reported cellular phenotype. This is significant in light of recent studies using brains of patients with schizophrenia and mood disorders; several laboratories have observed significant alterations related to oligodendrocytes in post-mortem brain, including decreased cell density and decreased expression of associated genes, such as myelin basic protein. ${ }^{38,47,48}$ Dysregulation of oligodendrocytes may be the root of the white matter abnormalities highlighted by diffusion tensor imaging studies in patients with schizophrenia and mood disorders, ${ }^{49,50}$ as well as the reduced connectivity observed in the dorsal attention and executive control networks by resting state functional magnetic resonance imaging. ${ }^{51}$ Oligodendrocyte abnormalities are also implicated in some animal models of schizophrenia. ${ }^{52}$

Given that aberrant cell cycle/fate control may be involved in the pathology of major mental illnesses, which cell(s) are the primary players? This study indicates that quetiapine treatment influences p21/Cdkn1a expression in OPCs and neurons in culture, whereas in the adult mouse brain, reduction of $\mathrm{p} 21 / \mathrm{Cdkn1a}$ was observed at least in postmitotic neurons. The functional consequence of changes to cell cycle-associated molecules, including p21/Cdkn1a, in adult postmitotic neurons is a fundamental biological question that is not yet well understood. It is likely that cell cycle-associated molecules and pathways play multiple, context-dependent roles in postmitotic neurons. In some brain disorders, it is suggested that the re-entry of postmitotic neurons into the cell cycle can lead to subsequent neuronal dysfunction and cell death, ${ }^{26,27}$ while in other situations cell cycle arrest may increase susceptibility to cell death. ${ }^{53}$ More specifically, p21/ Cdkn1a was found to act as the signal transducer that induces a senescence-like state in response to DNA damage, ${ }^{54}$ and as an antiapoptotic factor that mediates the neuroprotective effect of corticosterone. ${ }^{55}$ Although the role of cell cycleassociated molecules in postmitotic neurons is far from clear, we believe that our data provide novel insight and that quetiapine may be a useful pharmaceutical probe to address such crucial questions in the future. 
There are some important points raised in this study that will need consideration for future studies. Although the principal components analysis in this study indicated that drug dose was not a major source of variation in gene expression, it is a key consideration when translating data from preclinical studies to clinical application. In this study, we used a representative assay based on dopamine $D_{2}$ receptor blockade to determine the dose of neuroleptics for use in a preclinical model. If we simply compare the body weights between humans and mice, the doses of quetiapine used for mice in this study, 10 and $100 \mathrm{mg} \mathrm{kg}^{-1}$ b.i.d., correspond to approximately 700 and $7000 \mathrm{mg}$ b.i.d., assuming an average human of $70 \mathrm{~kg}$. Although this is obviously higher than the clinical dose, in many cases, a more rapid degradation of compounds is known in mice compared with humans. Therefore, in future studies, we will need to very carefully consider how to translate this preclinical data for clinical relevance.

This study also highlights the importance of brain region as a major source of variation in gene expression. The striatum is rich in dopamine $D_{2}$ receptors that underlie psychosis and are substrates for the binding of haloperidol and other typical neuroleptics. In contrast, this study focused on the frontal cortex with the aim of identifying new potential pathways that may account for the broader spectrum efficacy and novel actions of quetiapine. A recent paper from the Nester lab, ${ }^{56}$ utilizing optogenetic stimulation, highlighted the significance of medial prefrontal cortex activation in determining depression-like behavior. Thus, cortex-specific actions of quetiapine may be further addressed in conjunction with the biology of mood disorders.

Another question that should be addressed in future studies is whether p21/Cdkn1a directly contributes to mental function. Although the many molecular redundancies in cell cycle regulation may hamper straightforward data interpretation, revisiting knockout mice lacking p21/Cdkn1a, which develop normally at least at the gross physiological level, ${ }^{57}$ and crossbreeding with several different genetic models of psychiatric diseases, may be an avenue to address this question. Although the focus of this study was to elucidate the overall molecular impact of quetiapine treatment, future studies focusing on cell type-specific actions will be necessary to uncover which molecules, in which cells, serve as the receptor(s) that mediate the novel functions of this drug. Among the known transmembrane neurotransmitter receptors, quetiapine binds with highest affinity to adrenergic and histaminergic receptors. There has been one report that $\alpha 1$-adrenergic receptors have a role in cell cycle regulation. ${ }^{58}$ We speculate, however, that there may be an as yet undiscovered intracellular receptor(s) for quetiapine, analogous to the mTOR/FKBP12 protein complex for rapamycin and FK506. ${ }^{59,60}$ Although many neuroleptics can penetrate plasma membranes, there have been no serious attempts to identify intracellular receptors. Given the unique actions of quetiapine, this compound may be a good candidate for testing this idea.

\section{Conflict of interest}

The authors declare no conflict of interest.
Acknowledgements. We thank $\mathrm{Dr}$ Juan $\mathrm{C}$ Troncoso for guidance in histological analysis and Ms Yukiko Y Lema for assistance with the preparation of figures. AS was provided grant support by: MH-084018, MH-94268 Silvo O Conte center, MH-069853, MH-085226, MH-088753, MH-092443, Stanley, RUSK, S-R foundations, NARSAD and Maryland Stem Cell Research Fund; JP by: HD-24061 and MH-94268. This project is partly funded by Astellas Pharma.

1. Fribourg M, Moreno JL, Holloway T, Provasi D, Baki L, Mahajan R et al. Decoding the signaling of a GPCR heteromeric complex reveals a unifying mechanism of action of antipsychotic drugs. Cell 2011; 147: 1011-1023.

2. Kondo M, Sawa A. Anti-/propsychotic drug signaling via heteromeric GPCRs-a balancing act? Cell 2011; 147: 964-965.

3. Lehmann HE, Hanrahan GE. Chlorpromazine; new inhibiting agent for psychomotor excitement and manic states. AMA Arch Neurol Psychiatry 1954; 71: 227-237.

4. Carlsson A, Lindqvist M. Effect of chlorpromazine or haloperidol on formation of 3methoxytyramine and normetanephrine in mouse brain. Acta Pharmacol Toxicol (Copenh) 1963; 20: 140-144

5. Seeman $P$, Lee $T$. Antipsychotic drugs: direct correlation between clinical potency and presynaptic action on dopamine neurons. Science 1975; 188: 1217-1219.

6. Creese I, Burt DR, Snyder SH. Dopamine receptor binding predicts clinical and pharmacological potencies of antischizophrenic drugs. Science 1976; 192: 481-483.

7. Purdon SE, Malla A, Labelle A, Lit W. Neuropsychological change in patients with schizophrenia after treatment with quetiapine or haloperidol. J Psychiatry Neurosci 2001; 26: 137-149.

8. Woo TUW, Zimmet SV, Wojcik JD, Canuso CM, Green Al. Treatment of schizophrenia. In: Schatzberg AF, Nemeroff CB (eds). The American Psychiatric Publishing Textbook of Psychopharmacology. 4th edn American Psychiatric Publishers: Washington, DC, USA, 2009. pp 1135-1170.

9. Baune BT, Caliskan S, Todder D. Effects of adjunctive antidepressant therapy with quetiapine on clinical outcome, quality of sleep and daytime motor activity in patients with treatment-resistant depression. Hum Psychopharmacol 2007; 22: 1-9.

10. Bowden CL, Grunze H, Mullen J, Brecher M, Paulsson B, Jones M et al. A randomized, double-blind, placebo-controlled efficacy and safety study of quetiapine or lithium as monotherapy for mania in bipolar disorder. J Clin Psychiatry 2005; 66: 111-121.

11. McIntyre RS, Konarski JZ, Jones M, Paulsson B. Quetiapine in the treatment of acute bipolar mania: efficacy across a broad range of symptoms. J Affect Disord 2007; 100(Suppl 1): S5-S14.

12. Mclntyre RS, Soczynska JK, Woldeyohannes HO, Alsuwaidan M, Konarski JZ. A preclinical and clinical rationale for quetiapine in mood syndromes. Expert Opin Pharmacother 2007; 8: 1211-1219.

13. Mohr N, Vythilingum B, Emsley RA, Stein DJ. Quetiapine augmentation of serotonin reuptake inhibitors in obsessive-compulsive disorder. Int Clin Psychopharmacol 2002; 17: $37-40$.

14. Nemeroff CB, Kinkead B, Goldstein J. Quetiapine: preclinical studies, pharmacokinetics, drug interactions, and dosing. J Clin Psychiatry 2002; 63(Suppl 13): 5-11.

15. Richelson E, Souder T. Binding of antipsychotic drugs to human brain receptors focus on newer generation compounds. Life Sci 2000; 68: 29-39.

16. Richtand NM, Welge JA, Logue AD, Keck Jr PE, Strakowski SM, McNamara RK. Dopamine and serotonin receptor binding and antipsychotic efficacy. Neuropsychopharmacology 2007; 32: 1715-1726.

17. Shobo M, Kondo Y, Yamada H, Mihara T, Yamamoto N, Katsuoka M et al. Norzotepine, a major metabolite of zotepine, exerts atypical antipsychotic-like and antidepressant-like actions through its potent inhibition of norepinephrine reuptake. J Pharmacol Exp Ther 2010; 333: 772-781.

18. Wu Z, Irizarry RA, Gentleman R, Martinez-Murillo F, Spencer F. A model-based background adjustment for oligonucleotide expression arrays. J Am Statist Assoc 2004; 99: 909-917.

19. Subramanian A, Tamayo P, Mootha VK, Mukherjee S, Ebert BL, Gillette MA et al. Gene set enrichment analysis: a knowledge-based approach for interpreting genome-wide expression profiles. Proc Natl Acad Sci USA 2005; 102: 15545-15550.

20. Blackshaw S, Snyder SH. Developmental expression pattern of phototransduction components in mammalian pineal implies a light-sensing function. J Neurosci 1997; 17: 8074-8082.

21. Ozeki Y, Pickard BS, Kano S, Malloy MP, Zeledon M, Sun DQ et al. A novel balanced chromosomal translocation found in subjects with schizophrenia and schizotypal personality disorder: altered L-serine level associated with disruption of PSAT1 gene expression. Neurosci Res 2011; 69: 154-160.

22. Seshadri S, Kamiya A, Yokota Y, Prikulis I, Kano S, Hayashi-Takagi A et al. Disrupted-inschizophrenia-1 expression is regulated by beta-site amyloid precursor protein cleaving enzyme-1-neuregulin cascade. Proc Natl Acad Sci USA 2010; 107: 5622-5627.

23. Sawa A, Khan AA, Hester LD, Snyder SH. Glyceraldehyde-3-phosphate dehydrogenase: nuclear translocation participates in neuronal and nonneuronal cell death. Proc Natl Acad Sci USA 1997; 94: 11669-11674.

24. Cutler AJ, Goldstein JM, Tumas JA. Dosing and switching strategies for quetiapine fumarate. Clin Ther 2002; 24: 209-222. 
45. Xu H, Yang HJ, McConomy B, Browning R, Li XM. Behavioral and neurobiological changes in C57BL/6 mouse exposed to cuprizone: effects of antipsychotics. Front Behav Neurosci 2010; $4: 8$.

2009; 9: 400-414

26. Nagy Z. Cell cycle regulatory failure in neurones: causes and consequences. Neurobiol Aging 2000; 21: 761-769.

27. Herrup K, Yang Y. Cell cycle regulation in the postmitotic neuron: oxymoron or new biology? Nat Rev Neurosci 2007; 8: 368-378.

28. Benes FM, Lim B, Subburaju S. Site-specific regulation of cell cycle and DNA repair in postmitotic GABA cells in schizophrenic versus bipolars. Proc Natl Acad Sci USA 2009; 106: 11731-11736.

29. Bi X, Yan B, Fang S, Yang Y, He J, Li XM et al. Quetiapine regulates neurogenesis in ischemic mice by inhibiting NF-kappaB p65/p50 expression. Neurol Res 2009; 31 159-166.

30. He J, Luo H, Yan B, Yu Y, Wang H, Wei Z et al. Beneficial effects of quetiapine in a transgenic mouse model of Alzheimer's disease. Neurobiol Aging 2009; 30: 1205-1216.

31. Bian $Q$, Kato $T$, Monji A, Hashioka S, Mizoguchi $Y$, Horikawa $H$ et al. The effect of atypical antipsychotics, perospirone, ziprasidone and quetiapine on microglial activation induced by interferon-gamma. Prog Neuropsychopharmacol Biol Psychiatry 2008; 32 $42-48$.

32. Luo $\mathrm{C}, \mathrm{Xu} \mathrm{H}$, Li XM. Quetiapine reverses the suppression of hippocampal neurogenesis caused by repeated restraint stress. Brain Res 2005; 1063: 32-39.

33. Tanibuchi $Y$, Fujita $Y$, Kohno M, Ishima T, Takatsu Y, lyo $M$ et al. Effects of quetiapine on phencyclidine-induced cognitive deficits in mice: a possible role of alpha1-adrenoceptors. Eur Neuropsychopharmacol 2009; 19: 861-867.

34. Wang L, Lockstone HE, Guest PC, Levin Y, Palotas A, Pietsch S et al. Expression profiling of fibroblasts identifies cell cycle abnormalities in schizophrenia. J Proteome Res 2010; 9 ; 521-527.

35. Feron F, Perry C, Hirning MH, McGrath J, Mackay-Sim A. Altered adhesion, proliferation and death in neural cultures from adults with schizophrenia. Schizophr Res 1999; 40: 211-218.

36. McCurdy RD, Feron F, Perry C, Chant DC, McLean D, Matigian N et al. Cell cycle alterations in biopsied olfactory neuroepithelium in schizophrenia and bipolar I disorder using cell culture and gene expression analyses. Schizophr Res 2006; 82: 163-173.

37. Fan Y, Abrahamsen G, McGrath JJ, Mackay-Sim A. Altered cell cycle dynamics in schizophrenia. Biol Psychiatry 2012; 71: 129-135.

38. Kerns D, Vong GS, Barley K, Dracheva S, Katsel P, Casaccia P et al. Gene expression abnormalities and oligodendrocyte deficits in the internal capsule in schizophrenia. Schizophr Res 2010; 120: 150-158.

39. Lucassen PJ, Stumpel MW, Wang Q, Aronica E. Decreased numbers of progenitor cells but no response to antidepressant drugs in the hippocampus of elderly depressed patients. Neuropharmacology 2010; 58: 940-949.

40. Golzio C, Willer J, Talkowski ME, Oh EC, Taniguchi Y, Jacquemont S et al. KCTD13 is a major driver of mirrored neuroanatomical phenotypes of the $16 \mathrm{p} 11.2$ copy number variant. Nature 2012; 485: 363-367.

41. Brandon NJ, Sawa A. Linking neurodevelopmental and synaptic theories of mental illness through DISC1. Nat Rev Neurosci 2011; 12: 707-722.

42. Valvezan AJ, Klein PS. GSK-3 and Wnt signaling in neurogenesis and bipolar disorder. Front Mol Neurosci 2012; 5: 1 .

43. Voleti B, Duman RS. The roles of neurotrophic factor and Wnt signaling in depression Clin Pharmacol Ther 2012; 91: 333-338.

44. Xiao L, Xu H, Zhang Y, Wei Z, He J, Jiang W et al. Quetiapine facilitates oligodendrocyte development and prevents mice from myelin breakdown and behavioral changes. Mol Psychiatry 2008; 13: 697-708.

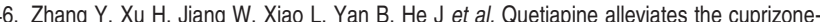
induced white matter pathology in the brain of C57BL/6 mouse. Schizophr Res 2008; 106 182-191.

47. Katsel P, Davis KL, Li C, Tan W, Greenstein E, Kleiner Hoffman LB et al. Abnormal indices of cell cycle activity in schizophrenia and their potential association with oligodendrocytes. Neuropsychopharmacology 2008; 33: 2993-3009.

48. Tkachev D, Mimmack ML, Ryan MM, Wayland M, Freeman T, Jones PB et al. Oligodendrocyte dysfunction in schizophrenia and bipolar disorder. Lancet 2003; 362 $798-805$

49. Sim K, Yang GL, Loh D, Poon LY, Sitoh YY, Verma S et al. White matter abnormalities and neurocognitive deficits associated with the passivity phenomenon in schizophrenia: diffusion tensor imaging study. Psychiatry Res 2009; 172: 121-127.

50. Cheung V, Cheung C, McAlonan GM, Deng Y, Wong JG, Yip L et al. A diffusion tensor imaging study of structural dysconnectivity in never-medicated, first-episode schizophrenia. Psychol Med 2008; 38: 877-885.

51. Woodward ND, Rogers B, Heckers S. Functional resting-state networks are differentially affected in schizophrenia. Schizophr Res 2011; 130: 86-93.

52. Katsel P, Tan W, Abazyan B, Davis KL, Ross C, Pletnikov MV et al. Expression of mutant human DISC1 in mice supports abnormalities in differentiation of oligodendrocytes. Schizophr Res 2011; 130: 238-249.

53. Yoshizawa T, Yamagishi Y, Koseki N, Goto J, Yoshida H, Shibasaki F et al. Cell cycle arrest enhances the in vitro cellular toxicity of the truncated Machado-Joseph disease gene product with an expanded polyglutamine stretch. Hum Mol Genet 2000; 9: 69-78.

54. Jurk D, Wang C, Miwa S, Maddick M, Korolchuk V, Tsolou A et al. Postmitotic neurons develop a p21-dependent senescence-like phenotype driven by a DNA damage response. Aging Cell 2012; 11: 996-1004

55. Harms C, Albrecht K, Harms U, Seidel K, Hauck L, Baldinger T et al. Phosphatidylinositol 3-Akt-kinase-dependent phosphorylation of $\mathrm{p} 21$ (Waf1/Cip1) as a novel mechanism of neuroprotection by glucocorticoids. J Neurosci 2007; 27: 4562-4571.

56. Covington HE III, Lobo MK, Maze I, Vialou V, Hyman JM, Zaman S et al. Antidepressan effect of optogenetic stimulation of the medial prefrontal cortex. J Neurosci 2010; 30 16082-16090.

57. Deng C, Zhang P, Harper JW, Elledge SJ, Leder P. Mice lacking p21CIP1/WAF1 undergo normal development, but are defective in G1 checkpoint control. Cell 1995; 82: 675-684.

58. Gonzalez-Cabrera PJ, Shi T, Yun J, McCune DF, Rorabaugh BR, Perez DM. Differential regulation of the cell cycle by alpha1-adrenergic receptor subtypes. Endocrinology 2004; 145: 5157-5167.

59. Sabatini DM, Erdjument-Bromage $H$, Lui M, Tempst $P$, Snyder SH. RAFT1: a mammalian protein that binds to FKBP12 in a rapamycin-dependent fashion and is homologous to yeast TORs. Cell 1994; 78: 35-43.

60. Brown EJ, Albers MW, Shin TB, Ichikawa K, Keith CT, Lane WS et al. A mammalian protein targeted by G1-arresting rapamycin-receptor complex. Nature 1994; 369: 756-758.

Translational Psychiatry is an open-access journal published by Nature Publishing Group. This work is licensed under a Creative Commons Attribution-NonCommercialNoDerivs 3.0 Unported License. To view a copy of this license, visit http://creativecommons.org/licenses/by-nc-nd/3.0/

Supplementary Information accompanies the paper on the Translational Psychiatry website (http://www.nature.com/tp) 